\title{
Proposta de telhado para futuras residências da região de mossoró-rn visando o melhor aproveitamento e instalação dos painéis solares
}

\author{
José Klaudyo Gurgel Nóbrega de Queiroz ${ }^{[1]}$, Francisco Magno Monteiro Sobrinho ${ }^{[2]}$ \\ ${ }^{[1]}$ Universidade Federal Rural do Semi-árido; klaudyo100@ hotmail.com. \\ ${ }^{[2]}$ Universidade Federal Rural do Semi-árido; magno.monteiro@ ufersa.edu.br
}

Recebido: 25/06/2019;

Aceito: 20/07/2019;

Publicado: 07/10/2019.

Resumo: O presente trabalho tem como objetivo identificar, analisar e propor a arquitetura de um telhado para futuras residências situadas na cidade de Mossoró no Rio Grande do Norte, visando um melhor aproveitamento da energia elétrica oriunda dos futuros painéis solares que venham a ser instalados sobre esse telhado no estado do Rio Grande do Norte, com isso foi analisado a irradiação, as telhas e tipo o de arquitetura do telhado que mais se adequaria ao estudo. Para isso, Foram realizados simulações e estudos bibliográficos de modo a promover a coleta de dados referentes as variantes do projeto, como irradiação global e inclinada, tipos de telha, posição do sol e tipo de telhado. Verificou-se a relação entre os fatores que interferem na eficiência e na instalação dos módulos, para com base nesses dados desenvolver a proposta que melhor concilia os fatores de instalação e eficiência.

Palavras-chave: Painéis solares; irradiação; telhado; angulação.

\section{INTRODUÇãO}

$\mathrm{D}$ evido a um crescente cenário de crise energética mundial, o assunto vem sendo amplamente debatido, ao mesmo tempo que a sua solução vem sendo um grande desafio para as nações. Pode-se identificar alguns fatores relacionados a esse problema, como a crescente demanda por energia, crise no petróleo, fontes energéticas poluentes e a potencial escassez dos recursos, que fazem com que esse cenário venha ficando cada vez mais critico e com incertezas [1].

Diante desse cenário, que vem se difundindo ao longo dos anos, iniciou-se uma busca por fontes alternativas e não poluentes de energia, e que possam vir a ser instaladas em áreas isoladas [1].

Nesse cenário mundial de crise energética o Brasil também se enquadra, visto que os níveis de água das barragens estão cada dia mais baixos, reduzindo a produção de energia elétrica por usinas hidroelétricas, as quais segundo [2] representam 63,81\% da energia gerada no Brasil. Com isso, o Brasil vem cada vez mais investindo em energias elétricas advindas de fontes renováveis e uma das principais é a geração de energia fotovoltaica que, segundo [3] o Brasil apresenta um grande potencial para sua geração, visto que possui um grande nível de irradiação solar, até maior que muitos países nos quais essa energia é amplamente incentivada, porém mesmo assim segundo [2], as centrais geradoras de energia solar fotovoltaica só representam 1,19\% da potência em operação, bem abaixo da energia eólica. A intensificação de projetos para aumentar a oferta de energias renováveis no Brasil veio, segundo [3], devido ao acordo firmado na Conferência das Nações Unidas sobre as Mudanças Climáticas de 2015 (COP 21), assinado no ano de 2015, no qual o Brasil se comprometeu a reduzir a emissão de gases do efeito estufa, em $37 \%$ até 2025 e em $43 \%$ até 2030, em relação aos níveis de 2005. De acordo com [4], o Brasil possui muitos incentivos para a geração de energia fotovoltaica, seja de grande ou pequeno porte, como o Programa Luz para Todos que, entre outros objetivos, tem o de instalar painéis fotovoltaicos em regiões que não tem acesso à energia elétrica, descontos na Tarifa de Uso dos Sistemas de Transmissão (TUST) e na Tarifa de Uso dos Sistemas de Distribuição (TUSD), Sistema de Compensação de 
Energia Elétrica para a Microgeração e Minigeração Distribuídas, como também o financiamento em condições diferenciadas, entre outros incentivos.

Com a crescente do cenário de geração de energia fotovoltaica e os incentivos governamentais, muitas pessoas físicas e microempresários veem aderindo a Microgeração e a Minigeração geração de energia distribuída e, por terem pouco espaço para instalação dos módulos, eles acabam por instalar os mesmos nos telhados onde a energia gerada será utilizada. Tendo em vista esse contexto, o presente trabalho tem o objetivo de identificar, analisar e propor uma arquitetura de telhado para futuras casas construídas na Cidade de Mossoró no estado do Rio Grande do Norte, com a finalidade de serem instalados painéis fotovoltaicos que venham a atingir a maior geração de energia elétrica possível, sem a necessidade de ajustes finos na base que os suportam. O artigo utiliza o método de pesquisa experimental, no qual selecionado o objeto de estudo e define as variáveis que podem influencia-lo. Desta forma, no presente projeto serão analisados através de softwares os níveis de irradiação solar no plano inclinado da região, como também o ciclo solar para identificar qual o melhor posicionamento e orientação do telhado, assim como as regiões adjacentes, com a finalidade de evitar problemas com o sombreamento.

\section{CONCEITOS RELACIONADOS À INSTALAÇÃO E GERAÇÃO DE ENERGIA FOTOVOLTAICA.}

\subsection{Radiação solar}

Segundo [5], a energia que o sol emite em um segundo é maior que toda a energia já consumida pelo homem em toda sua existência na Terra, com isso e baseado em [6], é possível considerar a radiação solar como a principal agente para processos térmicos, dinâmicos e químicos na Terra. Logo percebe-se que a energia advinda do sol pode ser utilizada em diversas áreas e como fonte de energia renovável devido ao seu alto nível de irradiância e a translação da Terra (que possibilita um ciclo de radiação).

Logo, a geração da energia depende da radiação solar que, de acordo com [6], é a quantidade de energia emitida em um dado comprimento de onda passar por uma área tomada perpendicularmente a direção, com isso deve-se também entender que a irradiância é basicamente a densidade de fluxo de radiação que está sobre uma determinada superfície.

A irradiação solar no topo da atmosfera, também chamada de constante solar, que tem o valor de aproximadamente $136 \mathrm{Wm}^{-2}$, pode variar ao longo do ano devido a efeitos advindos da translação, o comprimento da onda da radiação e de fenômenos que possam ocorrer no sol [6]. Porém, essa irradiação que chega ao topo da atmosfera terrestre, não é a mesma que chega ao solo, conhecido como o efeito de transmitância atmosférica, pois quando as ondas atravessam a atmosfera uma parte delas é espelhada e a outra parte é absorvida, sendo as nuvens, gases e partículas presentes na atmosfera responsáveis por refletirem cerca de $30 \%$ dependendo da região e do período do ano que se é observado [6].

Então, pode-se dizer que a irradiação que chega no solo pode ser dividida em duas, que de acordo com o entendimento de [7], é a direta e a difusa, onde a direta é a que não sofreu absorção ou espalhamento ao atravessar a atmosfera, e a difusa é a advinda dos processos de espelhamento. Onde [7] considera que essas irradiações possuem subdivisões:

Irradiância direta normal (Gn): é a irradiação direta do sol perpendicular à superfície; Irradiância difusa horizontal (Gdif): é a irradiação advinda do espelhamento dos rios solares por meio da atmosfera; Irradiância direta horizontal (Gdir): é a irradiação que incide sobre uma superfície horizontal; Irradiância global horizontal (G): é dada pela soma da Gdif com a Gdir; Irradiância no plano inclinado (Gi ): é a irradiação sobre uma dada área que esteja com a inclinação igual a da latitude da região.

Com base na Figura 1 uma das principais irradiâncias a serem analisadas é a direta horizontal.

Com base na Figura 2, é de fácil percepção que o Nordeste tem um gigantesco potencial para a geração de energia solar, visto que um dos principais pontos a se analisar o nível de irradiação do local, onde não só o Nordeste com mais precisamente a mesorregião do oeste potiguar apresenta um dos maiores índices de radiação global horizontal. 


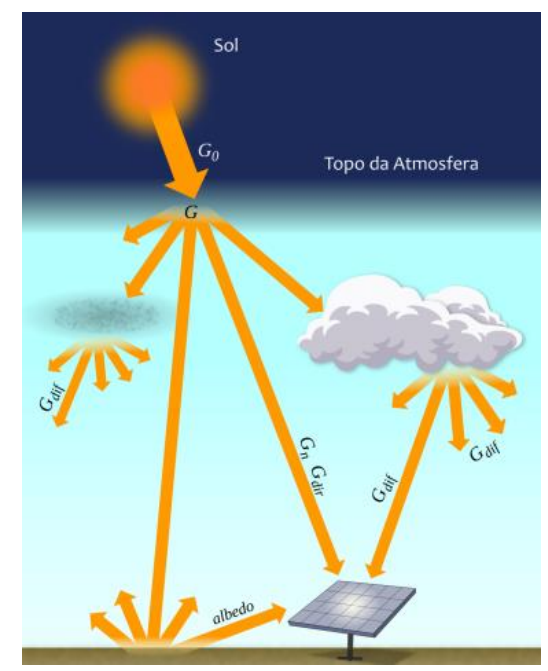

FIGURA 1. Componentes da irradiação solar. [7]

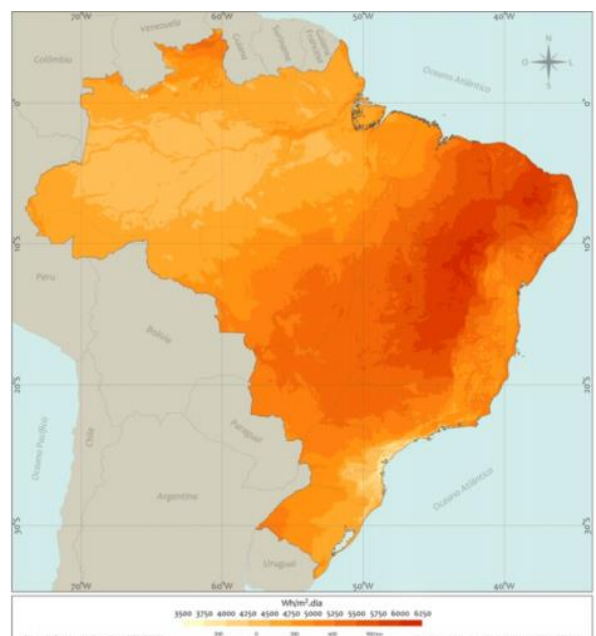

FIGURA 2. Média anual da radiação diária global horizontal. [7]

Devido a absorção de raios solares pelas partículas advindas da poluição, em regiões com alto nível de poluição, a radiação solar diária pode diminuir em 5\%, mas já para áreas mais afastadas do centro industrial, a radiação diária tem um ganho de $5 \%$ [7].

\subsection{Geometria solar}

A Terra apresenta dois principais movimentos, a rotação onde gira em torno do seu próprio eixo, e a translação que se resume na movimentação em torno do Sol [8]. Essas duas movimentações possuem suma importância no nível de irradiação que a Terra irá receber em determinadas épocas do ano e regiões.

O processo completo de rotação dura 24 horas e ocorre no sentido anti-horário fazendo com que o Sol venha a aparecer no Leste, tenha seu ponto máximo ao meio-dia e se oculte no oeste. É essa movimentação que determina a sucessão do dia e da noite, pois durante a rotação metade da Terra recebe raios solares, assim sendo considerado dia, e a outra metade não recebe, sendo considerado noite [8].

A translação é um processo no qual a Terra percorre uma trajetória elíptica com o Sol em seu centro que dura 365 dias e 6 horas, fazendo com que a cada 4 anos se tenha o chamado ano bissexto com 366 dias, com o objetivo de corrigir a diferença de horas restantes da movimentação. Segundo [7], o processo de translação ocorre devido a inclinação de $23,45^{\circ}$ que o eixo da Terra tem em relação ao plano orbital do sol. Devido a essa inclinação o ângulo que é formado pela inclinação do plano equatorial da Terra e a linha de orientação da Terra em relação ao Sol chega a variar $47^{\circ}$. De acordo com [8] se essa inclinação não existisse os dias e as noites teriam a mesma duração em todos os lugares da Terra, mas isso acontece, pois, a Terra não fica na mesma posição em relação ao Sol durante o ano. 
Segundo [9], a duração dos dias e das noites depende da estação do ano, como no hemisfério sul, que no dia 21 de dezembro ocorre o solstício de verão que é quando o dia tem sua maior duração, pois o Sol está em sua posição mais ao norte em relação a Terra. Enquanto no hemisfério norte é o contrário. Baseado em [8], entre esse período nos dias 21 de março e 23 de setembro, ocorrem os equinócios que é quando a noite e o dia possuem o mesmo tempo, esse evento ocorre nos dois hemisférios ao mesmo tempo, pois nessas datas a reta entre o centro da Terra e o centro do Sol cortam o globo terrestre em um ponto paralelo de latitude $0^{\circ}$, fazendo com que os raios advindos do sol tenham direção perpendicular em relação a linha do Equador.

Considerando as convenções da declinação solar e da latitude, sendo positivas ao Norte e negativas ao Sul, e fazendo a diferença entre a latitude e a declinação, pode-se determinar a trajetória do Sol em um determinado dia e em uma região específica [10]. De modo geral, a declinação solar pode ser dada pela equação (1):

$$
\sin (\delta)= \pm \sin (23,45) \cos \left[\left(\frac{360}{365,25}\right)(n+10)\right]
$$

Onde $n$ representa o dia em que se quer saber a declinação solar.

\subsubsection{Inclinação dos painéis fotovoltaicos}

Segundo [1], para encontrar a inclinação ideal de um painel fotovoltaico, deve-se levar em consideração a latitude do local e o tipo de sistema que será utilizado. Pois quando se trata de um painel de sistema isolado, é indicado utilizar uma angulação maior, para garantir maior captação de raios solares, nos períodos próximos ao solstício de inverno. Mas já para sistemas conectados à rede elétrica, inclinações menores proporcionam uma maior captação nos períodos próximos ao solstício de verão, o que gera mais energia, em período mais curtos, fazendo com que o proprietário venha a ter ganhos econômicos devido ao sistema de créditos das empresas responsáveis.

Como o Brasil está em uma posição privilegiada, e próximo a linha do Equador, e no hemisfério sul é mais indicado que os painéis fotovoltaicos sejam instalados com um grau de inclinação (com relação ao plano horizontal da superfície) menor que a latitude do local onde serão instalados os painéis fotovoltaicos.

Também de acordo com [5], outro ponto importante é que o valor mínimo de inclinação seja $10^{\circ}$, pois uma inclinação inferior a essa, atrapalha a limpeza natural dos módulos, podendo até causar acúmulo de água e sujeira, fazendo com que seja necessária uma maior quantidade de manutenção.

\subsubsection{Softwares para determinação da inclinação de painéis fotovoltaicos}

Um dos softwares que pode ser usado é o SunData®, que é um sistema criado pelo Centro de Referência para Energia Solar e Eólica Sérgio de Salvo Brito (CRESESB), que serve de apoio para o dimensionamento de sistemas fotovoltaicos, visto que o programa destina-se a calcular a irradiação solar diária média mensal em qualquer região do Brasil quando informada a latitude e longitude.

O software utiliza o banco de dados do Atlas Brasileiro de Energia Solar - 2a Edição, que foi produzido durante 1999-2015 com imagens de satélite, e contém informações de mais de 72 mil pontos em toda a extensão territorial brasileira.

Outro programa que também pode ser utilizado para a determinação de inclinação de um painel fotovoltaico é o RADIASOL2, que foi desenvolvido Universidade Federal do Rio Grande do Sul (UFRGS) no projeto SOLARCARD, que tem como objetivo simular o comportamento real dos componentes do sistema fotovoltaico a partir de parâmetros específicos.

O RADIASOL2 é baseado em cálculos trigonométricos e modelos de distribuição espacial e temporal, que foram desenvolvidos por integrantes do projeto SOLARCARD ou por autores da literatura ligados a irradiação solar. O software realiza os cálculos com base em rotinas que indicam o efeito da inclinação na área que irá receber a irradiação como também nas componentes diretas e difusas da radiação solar. Além disso, é válido ressaltar que os dados gerados pelo RADIASOL2 são apresentado em forma de tabela ou de gráfico.

\subsubsection{Orientação do painel fotovoltaico}

A orientação dos painéis fotovoltaicos deve se basear no ponto azimutal, formando um ângulo de superfície igual a zero. Seu ponto de base para o azimute é o Equador, com isso os painéis localizados no hemisfério sul devem ser orientados para o Norte, enquanto que os localizados no hemisfério norte devem seguir a orientação para o Sul [5]. Como também devem ser evitados ângulos superiores a $30^{\circ}$, para o leste ou para o oeste, visto que a cada $15^{\circ}$ de desvio do norte geográfico se tem uma hora de diferença para a capitação máxima, 
que se for para o Leste haverá um adiantamento e para o Oeste um atraso. Com isso e baseado em [11] apud [12], para se aproveitar melhor a irradiação solar, os painéis devem ser orientados em dois eixos, porem dessa forma o sistema fica mais caro e com mais custos de manutenção. O que é representado na Figura 3.
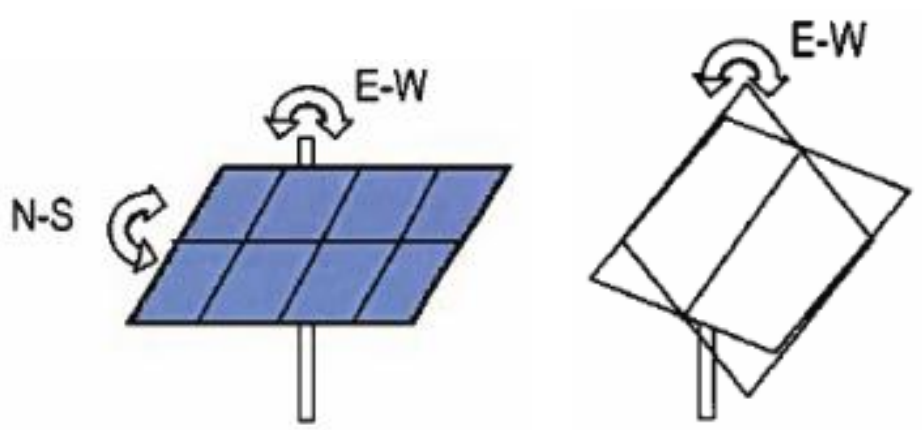

FIGURA 3. Orientação dos painéis em dois eixos e um eixo (respectivamente). [12]

Normalmente para painéis fixos utiliza-se a latitude mais $15^{\circ}$ quando no inverno e a latitude menos $15^{\circ}$ quando no verão, esses ângulos servem com indicação para a maximização da radiação solar que incide sobre os painéis nas estações do ano. Normalmente os painéis são instalados com base na inclinação de verão, visto que a estação do ano que mais tem exposição ao sol e uma fraca ocorrência de nuvens [12].

\subsection{Sombreamento dos painéis fotovoltaicos}

Com base no programa Alemão dos "1000 telhados", foi observado que quase metade dos sistemas possuem um sombreamento parcial, devido a circunstâncias específicas, como a sua localização. Com isso, foi observado também que essas sombras provocam uma redução da produção de energia anual de 5 a $10 \%$. Os sombreamentos são classificados em três tipos; temporários, como consequência da localização do sistema; e produzido pelo edifício [13].

O sombreamento temporário, é a presença de neve, folhas e/ou dejetos de pássaros, como também outros tipos de sujidade. Os agentes causadores desse tipo de sombreamento podem acabar manchando a superfície geradora, formando assim sombras de maior permanência. Por isso, sistemas instalados em áreas florestais e com indústrias ao redor devem observar bem esse tipo de sombreamento. Os piores causadores desse sombreamento são as folhas, a poluição do ar e os dejetos dos pássaros, pois causam um impacto mais forte e mais duradouro, mesmo que em uma localização normal e com painéis na declividade correta. A perda devido a esses tipos de agentes varia de 2 a 5\%, que uma perda é normalmente aceita. Porém se houver grande acumulação de resíduos os painéis devem ser limpos com água e utensílios leves de limpeza, a fim de evitar qualquer risco nas placas fotovoltaicas [13].

Já o sombreamento consequente da localização, é todo o sombreamento produzido pelas áreas próximas ao edifício. Como os prédios vizinhos e as árvores, que tendem a sombrear os painéis fotovoltaicos e/ou levar ao escurecimento do horizonte. Também é exemplo desse tipo de sombreamento cabos próximos aos módulos, que tendem a projetar sombras que se movem constantemente [13].

A última é o sombreamento produzido pelo edifício, ou seja, são as sombras causadas pela arquitetura da edificação. Essas sombras são constantes, por isso devem ser consideradas de uma forma mais particular. Os seus principais exemplos são as chaminés, antenas, para-raios, ressaltos da estrutura, entre outros. Com isso, ao fazer o projeto para a instalação dos módulos deve-se deslocar os painéis ou o objeto causador da sombra [13].

\subsubsection{Análise do sombreamento}

Para a análise de sombreamento é necessário o contorno da sombra do meio circundante para um ponto do sistema, que normalmente é o central, e ele pode ser obtido por mapas de trajetória solar, por analisador de sombras (softwares), e pelo plano do local e através do mapa de trajetória solar.[13]

Quando é utilizado um plano do local e um mapa de trajetória solar, deve-se calcular a distância e as dimensões projetadas pelos objetos, com o fim de calcular o ângulo do azimute e de elevação. O ângulo de elevação deve ser obtido para todos os obstáculos que rodeiam o sistema solar, com isso é necessário conhecer a altura e a distância dos objetos a partir do local de observação. Os ângulos de elevação e de azimutes do objeto 
também podem ser determinados com a utilização de câmeras apropriadas. Normalmente quando se quer uma maior precisão se utiliza os softwares, que em sua maioria calculam as perdas de irradiação e com base nelas, calculam as perdas de energia. É comum os softwares utilizarem, somente um ponto, que normalmente já é o suficiente, porém, há alguns mais eficientes como o PV-Cad. e o PV-SYST, que levam em consideração a geometria do gerador e o modo em que estão ligados.[13]

\subsubsection{Efeito do sombreamento}

Segundo [14], normalmente os painéis fotovoltaicos são formados por um determinado número de células associadas em série. Por causa, disso as células que forem sombreadas podem funcionar como carga para as demais células ocasionando uma grande dissipação de potência sobre elas, que por fim, causa o fenômeno conhecido com hotspot (pontos quentes), que é um aquecimento exagerado nas células que causam danos permanentes as células. Completando com um exemplo de [5], se uma folha cair e acabar encobrindo uma célula, a mesma será inversamente polarizada e passará a agir como uma carga, com isso irá converter a eletricidade em calor, e isso acaba gerando um hotspot, pois a maior corrente que essa célula poderia receber é a de curto-circuito.

De acordo com [14], para se evitar os hot-spots são utilizados os diodos de bypass, que são conectados em antiparalelo com as células. Esse diodo funciona da seguinte forma: quando a célula não possui problema de identidade em relação as demais e não for sombreada, o diodo fica reversamente polarizado, fazendo com que não passe corrente elétrica por ele, porém quando a célula estiver sombreada, o diodo ficará diretamente polarizado, fazendo com que por ele circule corrente. Nesse caso a célula sombreada não irá produzir energia elétrica, como também não vai produzir carga para as outras células.

Com base em [14], também deve-se ter atenção com as correntes reversas advindas de outros painéis, que também podem ser evitadas com a utilização de diodos, mas nesse caso o diodo de bloqueio, que são conectadas em série com os painéis. Essas correntes são causadas pela diferença de tensão entre os painéis, por causa dos sombreamentos, onde a placa fotovoltaica com menor tensão acaba por se tornar uma carga para os demais painéis, com isso a corrente gerada pelas outras placas fotovoltaicas fluirá pelo painel de menor tensão, causando um aquecimento nesse de menor tensão, e consequentemente, uma diminuição na potência do sistema.

\subsection{Telhados}

Segundo [15], quanto ao aspecto civil da edificação, de grande importância a escolha do tipo de telhado a ser utilizado na obra, visto que ele pode influenciar muito o projeto estrutural e desempenho futuro da instalação fotovoltaica. Também com base em [15], para a instalação de módulos de geração fotovoltaica, deve-se vistoriar os telhados/coberturas das edificações onde serão instalados os mesmos. Indica-se que essa vistoria seja feita por no mínimo dois profissionais visto a necessidade de escalar para acessar o telhado, onde é verificado se realmente a estrutura suportará ao projeto executivo. Para isso, são observado, em caso de telhados cerâmicos sustentados por madeiras, as condições dos caibros, e no caso de estruturas metálicas, examina-se os sinais de deterioração, assim como observa-se a capacidade estrutural do telhado, e avalia-se se os pontos de fixação estão em condições apropriadas. Também deve-se ter cuidado na instalação e limpeza dos painéis em telhados com telhas cerâmicas com o fim de evitar o trincamento delas. Como se trata de um projeto que ficará por mais de 20 anos, essas verificações devem ser bem-feitas, com o intuito de evitar ter que retirar os painéis para fazer um conserto no telhado.

Uma parte fundamental para a melhor eficiência de um módulo fotovoltaico é a sua inclinação, com isso é de grande importância ter conhecimento da inclinação do telhado, que é dada pela seguinte formula:

$$
h=v \times i
$$

Onde $\mathrm{h}$ corresponde a componente horizontal do telhado, v a vertical e i a inclinação dada em porcentagem $(\%)$

Vários tipos de telha são comercializados no Brasil, com a cerâmica que é subdividida em cinco tipos: a de concreto, a esmaltada, de fibrocimento, a galvanizada e a gravilhada. Porém, as mais utilizadas em Mossoró são as de fibrocimento e a cerâmica.

Segundo [16] a telha cerâmica deve possuir uma inclinação entre $32 \%$ e $40 \%$, porém se as telhas forem fixadas com arames, através da orelha da aramar a estrutura de apoio do telhado, como é ilustrado na Figura 4, pode-se utilizar uma declividade maior. Além de, que quando se for fazer uma averiguação da situação do 
telhado não se deve pisar diretamente nas telhas, com isso é indicado a utilização de tábuas para a divisão dos esforços.

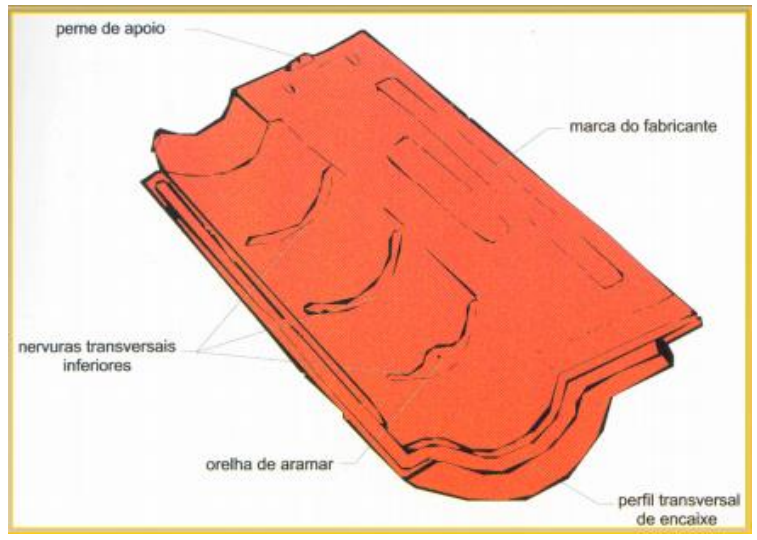

FIGURA 4. Detalhes da telha. [17]

Já a telha de fibrocimento, de acordo com [18], tem várias divisões e a do tipo tropical pode ter inclinação de $10^{\circ}$ a $30^{\circ}$ e a ondulação de $6 \mathrm{~mm}$ e $8 \mathrm{~mm}$ tem a inclinação mínima de $5^{\circ}$, porem são recomendados $15^{\circ}$. Também é indicado não pisar diretamente na telha, para evitar acidentes, trincas e vazamentos, que também podem ser causados por uma excessiva força na fixação dos painéis.

\section{MetOdOLOGIA}

O artigo está inserido na área de pesquisa de Engenharia Civil. Quanto a sua finalidade, é uma pesquisa do tipo aplicada, pois de acordo com [19] esse tipo de pesquisa é voltado para a aquisição de conhecimentos a serem aplicados em uma situação específica. Quanto a abordagem é uma pesquisa quantitativa, de acordo com [20], esse tipo de pesquisa tem como principal característica expressar por medidas numéricas fatos, informações, dados e opiniões, que posteriormente serão analisados. Quanto aos métodos, é uma pesquisa experimental em razão de que [19] diz que esse tipo de pesquisa consiste basicamente em escolher um objeto de estudo, verificar as variáveis que pode influenciá-lo de definir formas de controle e observação dessas variáveis.

\subsection{Determinação do objeto de estudo}

O objeto central de estudo é a arquitetura de um telhado para futuras casas na cidade de Mossoró, que venha a possibilitar uma melhor eficiência e instalação de painéis fotovoltaicos. Com isso, deve-se unir em uma só arquitetura, um telhado que possa receber a maior quantidade de irradiação solar em plano inclinado, porém dentro das normas preestabelecidas para as estruturas e evitando sombreamentos.

\subsection{Analise da Irradiação}

Com auxilio do software RADIASOL2, foi gerado uma simulação dos níveis de irradiação solar para a localização da cidade de Mossoró que possui a latitude de $05^{\circ} 1^{\prime} 1^{\prime} 15^{\prime \prime}$ ao sul de acordo com [21]. Com a finalidade de se obter os dados de irradiação global, direta e inclinada com relação a angulação de $4^{\circ}$ e azimute de $0^{\circ}$ em relação ao Norte.

TABELA 1. Irradiação Média (kWh/m²/dia) com a angulação de $4^{\circ}$.[22].

\begin{tabular}{cccc}
\hline Mês & Global & Direta & Inclinada \\
\hline 1 & 5,37 & 2,73 & 5,27 \\
\hline 2 & 5,35 & 2,78 & 5,3 \\
\hline 3 & 5,07 & 2,5 & 5,1 \\
\hline 4 & 4,8 & 2,36 & 4,89 \\
\hline
\end{tabular}




\begin{tabular}{cccc}
\hline 5 & 4,99 & 2,95 & 5,14 \\
\hline 6 & 4,66 & 2,68 & 4,83 \\
\hline 7 & 5,05 & 3,06 & 5,22 \\
\hline 8 & 5,88 & 3,88 & 6,02 \\
\hline 9 & 6,02 & 3,75 & 6,08 \\
\hline 10 & 6,38 & 3,86 & 6,34 \\
\hline 11 & 6,38 & 3,9 & 6,25 \\
\hline 12 & 5,91 & 3,52 & 5,76 \\
\hline
\end{tabular}

Após a primeira simulação foi feita uma segunda, porém com a inclinação de $10^{\circ}$, visto que é a inclinação indicada pelo programa. Nessa segunda simulação foram mantidas todas as informações da primeira, como localização e azimute em relação ao Norte.

TABELA 2. Irradiação Média (kWh/m²/dia) com a angulação de $10^{\circ}$. [22].

\begin{tabular}{cccc}
\hline Mês & Global & Direta & Inclinada \\
\hline 1 & 5,38 & 2,56 & 5,08 \\
\hline 2 & 5,35 & 2,5 & 5,21 \\
\hline 3 & 5,07 & 2,44 & 5,1 \\
\hline 4 & 4,8 & 2,52 & 4,99 \\
\hline 5 & 4,99 & 2,96 & 5,33 \\
\hline 6 & 4,66 & 2,77 & 5,06 \\
\hline 7 & 5,05 & 3,38 & 5,45 \\
\hline 8 & 5,88 & 4,01 & 6,19 \\
\hline 9 & 6,02 & 3,72 & 6,13 \\
\hline 10 & 6,38 & 3,79 & 6,25 \\
\hline 11 & 6,38 & 3,7 & 6,02 \\
\hline 12 & 5,91 & 3,13 & 5,5 \\
\hline
\end{tabular}

Comparando as duas tabelas é perceptível que quando angulado em $4^{\circ}$ os painéis terão um total de 66,20 $\left(\mathrm{kWh} / \mathrm{m}^{2} /\right.$ dia) e quando angulado em $10^{\circ}$ tem um total de $66,31\left(\mathrm{kWh} / \mathrm{m}^{2} /\right.$ dia $)$. Porém deve-se observar que quando inclinado em $4^{\circ}$, os painéis possuem uma grande eficiência nos meses de verão, que são os mais importante para geração de energia visto que são os meses nos quais os dias possuem mais tempo de radiação solar.

\subsection{Analise da telha}

No mercado encontra-se vários tipos de telhas, mas o presente artigo vai analisar as cerâmicas, as de concreto e as de fibrocimento, por serem as mais fácil aquisição na cidade de Mossoró.

O telhado cerâmico é o mais comum em edificações não só na mesorregião Potiguar, como em todo o Brasil, devido a facilidade de ser encontrado no mercado e sua ampla variedade no qual serão avaliados cinco tipos, que são os mais comuns.

TABELA 3. Características da telha cerâmica. [23] adaptado.

\begin{tabular}{cccc}
\hline Tipo de telha & Inclinação & Carga de & Numero de \\
cerâmica & mínima $(\%)$ & ruptura média & telhas $/ \mathrm{m}^{2}$ \\
& & $(\mathrm{kgf})$ & \\
\hline
\end{tabular}




\begin{tabular}{cccc}
\hline Mediterrânea & 30 & 468 & 14,5 \\
\hline Romana (14) & 30 & 280 & 14 \\
\hline Italiana & 30 & 305 & 14 \\
\hline Romana & 30 & 280 & 16 \\
\hline Francesa & 32 & 70 & 15 \\
\hline
\end{tabular}

O telhado de concreto ainda é pouquíssimo utilizado no Brasil, só sendo empregado em obras de alto custo, e segundo [21], tem como principais características, o fácil manuseio, resistência a intempéries e baixo índice de absorção da água.

TABELA 4. Características da telha de concreto. [23] adaptado.

\begin{tabular}{cccc}
\hline Tipo de telha & $\begin{array}{c}\text { Inclinação } \\
\text { mínima }(\%)\end{array}$ & $\begin{array}{c}\text { Resistência } \\
\left(\mathrm{kgf} / \mathrm{m}^{2}\right)\end{array}$ & $\begin{array}{c}\text { Numero de } \\
\text { telhas } / \mathrm{m}^{2}\end{array}$ \\
\hline $\begin{array}{c}\text { Concreto do } \\
\text { tipo americano }\end{array}$ & 30 & 2400000 & 10,4 \\
\hline
\end{tabular}

O telhado de fibrocimento é muito encontrado em construções mais populares, devido ao seu baixo custo, e outras vantagens é sua rápida e seu menor custo de instalação por ser um material mais leve.

TABELA 5. Características da telha de fibrocimento. [18] adaptado.

\begin{tabular}{ccc}
\hline Tipo de telha & Inclinação mínima $(\%)$ & Resistência $(\mathrm{kgf} / \mathrm{m} 2)$ \\
\hline Telhado ondulado $(6 \mathrm{~mm})$ & 9 & 330 \\
\hline Telhado ondulado $(8 \mathrm{~mm})$ & 9 & 425 \\
\hline Tropical $(5 \mathrm{~mm})$ & 18 & 250 \\
\hline
\end{tabular}

\subsection{Estrutura do telhado quanto ao numero de águas}

O número de águas refere-se basicamente a quantidade de orientações que o telhado tem, bem com para quantos lados irá escoar a água devinda da chuva, seja o telhado de uma água é um telhado com uma única declividade e orientação, onde sua maior utilidade é em coberturas de garagens e varandas, e é aquele que apresenta o menor custo de instalação. Já o telhado de duas águas ele normalmente possui duas declividades iguais, mas opostas, fazendo com que a água da chuva caia em duas direções. O telhado de três águas é muito utilizado em edificações triangulares por ser um telhado que divide a água em três orientações. Assim por diante, podendo ter telhados com inúmeras águas dependendo do projeto e da necessidade.

\section{RESULTADO}

Como a área analisada está localizada em uma região muito privilegiada geograficamente devido a sua posição em relação a linha do Equador sabe-se que terá uma grande irradiação solar até mesmo com diferentes orientações. Porém como está no hemisfério sul e baseado na Tabela 1 percebe-se que a melhor inclinação gira em torno de $4^{\circ}$, mas a inclinação mínima para um painel fotovoltaico é de $10^{\circ}$, pois, segundo a norma, uma angulação inferior a essa impede a autolimpeza dos painéis, que seria basicamente ao chover limpar as placas ou os objetos deslizarem mais facilmente, porém se a angulação for inferior a determinada angulação a água pode ficar retida na parte inferior dos módulos como também outros agentes de sujidade assim, podendo até causar manchas nos painéis, o que reduz consideravelmente sua geração. Com isso, sabe-se que a angulação mínima é de $10^{\circ} \mathrm{e}$, por estar no hemisfério sul, a inclinação para maior irradiação tende a estar abaixo da latitude e o mais perto aceitável pela norma é $10^{\circ}$, e a irradiação para essa angulação pode ser observada na tabela 2 . Outro ponto é o azimute em relação ao sol, mas com indicado por estar, próximo a linha do Equador, o azimute mais indicado é 0 ou próximo de zero, o que foi comprovado em simulações feitas no software RADIASOL.

Visto que a melhor angulação possível é de $10^{\circ}$, as telhas mais indicas são as de fibrocimento, uma vez que são as únicas que podem ser utilizadas nessa inclinação sem grandes problemas. A do tipo ondulado de $6 \mathrm{e}$ 
8 milímetros, podem ser utilizados em ate $5^{\circ}$ e a do topo tropical pode ser utilizada em ate $10^{\circ}$. E entre essas 3 , a mais indicada é a ondulada de $8 \mathrm{~mm}$ visto que é a que possui uma maior resistência, algo que é muito importante devido a longa duração dos módulos e que durante sua instalação o telhado estará sob pressão. Como também esse telhado facilita a instalação das bases que sustentam os painéis, tem um baixo custo e uma rápida instalação. Sabendo que o telhado é do tipo de fibrocimento, haverá um grande ganho econômico se o telhado possuir uma única água pois não serão usadas ripas diminuindo o gasto com as mesmas, além de uma mais rápida montagem e uma maior área para a instalação de painéis fotovoltaicos.

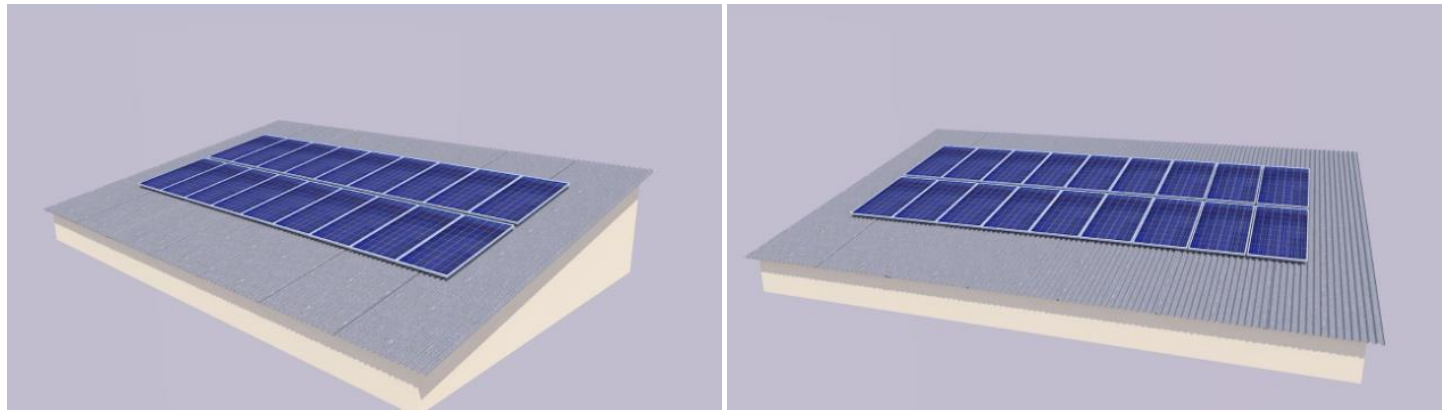

FIGURA 5. Proposta de telhado. (Autoria própria)

Com isso o telhado para a melhor eficiência e instalação dos painéis fotovoltaicos, é o de uma água, com telha de fibrocimento, do tipo ondulada de $8 \mathrm{~mm}$ e com angulação de $10^{\circ}$. Para fins de melhor estética pode-se utilizar o telhado de forma embutido porém tendo cuidado com o possível sombreamento assim localizando os painéis de forma mais central possível.

\section{CONCLUSÃO}

O presente trabalho se propôs a apresentar uma arquitetura para telhados que venham a ser construídos na cidade de Mossoró no estado do Rio Grande do Norte, no que diz respeito a uma maior eficiência de painéis fotovoltaicos e sua mais fácil instalação, com isso foram analisados vários fatores, que influenciam diretamente no rendimento dos painéis fotovoltaicos, e seu grau de importância visto que um fator esta relacionado com o outro, assim tendo que encontrar um equilíbrio entre ambos.

Depreendeu-se que, a cidade de Mossoró por esta muito bem localizada geograficamente, mesmo com diferentes orientações não tem uma grande perda de geração. Entretanto foi constatado através de simulações com o software RADIASOL2 a melhor angulação e azimute dentro das normas para a instalação de painéis fotovoltaicos na região analisada. No que diz respeito a estrutura, foi encontrada uma que pudesse facilitar a instalação e manutenção dos painéis, além de possuir uma boa área para uma colocação maior de painéis.

Vê-se a importância deste trabalho de forma a disseminar o melhor formato para a construção de telhados que visão a instalação de pineis fotovoltaicos, bem como os fatores que influenciam a eficiência de um painel fotovoltaico, além de apresentar uma forma mais barata para a construção de um telhado seguindo as normas já vigentes.

Devido ao trabalho não apresentar o estudo que relaciona a eficiência do painel fotovoltaico com a temperatura do mesmo, fator que pode gerar uma maior quantidade de energia produzida, assim sendo sugerido um estudo com essa finalidade. Uma das indicações de programas para a esse estudo é o Energyplus e Desing Builder, os quais são programas nos quais se pode fazer uma avaliação termo energética mais detalhada.

\section{REFERÊNCIAS}

[1] CABRAL, I; VIEIRA, R. VIABILIDADE ECONÔMICA X VIABILIDADE AMBIENTAL DO USO DE ENERGIA FOTOVOLTAICA NO CASO BRASILEIRO: UMA ABORDAGEM NO PERÍODO RECENTE. em: Congresso Brasileiro de Gestão Ambiental, $3^{\circ}$, 2012, Goiânia, Góis. p.1.

[2] BANCO DE INFORMAÇÕES DE GERAÇÃO. Capacidade de Geração do Brasil. Disponível em: < http://www2.aneel.gov.br/aplicacoes/capacidadebrasil/capacidadebrasil.cfm>. Acesso em: 8 de fevereiro de 2019. 
[3] NASCIMENTO, Rodrigo Limp. ENERGIA SOLAR NO BRASIL: SITUAÇÃO E PERSPECTIVAS. Câmara dos Deputados, Consultoria Legislativa, [S.L], p. 4, mar. 2018. Disponível em: <http://bd.camara.leg.br/bd/handle/bdcamara/32259>. Acesso em: 18 out. 2018.

[4] SILVA, R. M. Energia Solar no Brasil: dos incentivos aos desafios. Brasília: Núcleo de Estudos e Pesquisas/CONLEG/Senado, Fevereiro/2015 (Texto para Discussão n ${ }^{\circ}$ 166). Disponível em: www.senado.leg.br/estudos. Acesso em 3 de fevereiro de 2019.

[5] SOUZA, Ronilson di. Os sistemas de energia solar fotovoltaica: Livro digital de introdução aos sistemas solares. Elaborado para dar suporte a clientes da empresa BlueSol. Disponível em: $<$ http://programaintegradoronline.com.br/wp-content/uploads/2016/03/Livro-Digital-deIntrodu\%C3\%A7\%C3\%A3o-aos-Sistemas-Solares-novo.pdf>. Acesso em: 09 fev. 2019.

[6] MARTINS, F. A.; PEREIRA, E. B.; ECHER, M. P. S. Levantamento dos recursos de energia solar no Brasil com o emprego de satélite geoestacionário - o Projeto Swera. Revista Brasileira de Ensino de Física, v. 26, n. 2, p. 145 - 159, 2004. Disponível em: 〈http://www.scielo.br/pdf/rbef/v26n2/a10v26n2〉. Acesso em: 04 de janeiro de 2018.

[7] RÜTHER, Ricardo et al. Atlas Brasileiro de Energia Solar 2a . São José dos Campos: INPE, 2017. Disponível

$\mathrm{em}:<$ http://ftp.cptec.inpe.br/labren/publ/livros/Atlas_Brasileiro_Energia_Solar_2a_Edicao.pdf.>.

[8] ALVES, Sergio. A Geometria do Globo Terrestre. em: II Bienal da Sociedade Brasileira de Matemática, 2004, Salvador. Processamento... OBMEP: 19/02/2009. p 1-81.

[9] KALOGIROU, Soteris. Solar energy engineering: processes and systems. United States: Elsevier, 2009.

[10] Centro de Pesquisas de Energia Elétrica. Centro de Referência para Energia Solar e Eólica Sérgio de Salvo Brito. Grupo de Trabalho de energia Solar. Manual de Engenharia Para Sistemas Fotovoltaicos. Rio de Janeiro: CRESESB, MARÇO DE 2014. Disponível em:< http://www.cresesb.cepel.br/index.php?section=publicacoes \&task=livro\&cid=481>. Acessado em: 06 de janeiro de 2019.

[11] Camus, Cristina e Eusébio, Eduardo, "Energia Solar" , Março de 2006.

[12] RICARDO. J. C. L. EFEITO DO SOMBREAMENTO NOS PAINÉIS FOTOVOLTAICOS: 2013. 111p. Dissertação (Mestrado) - Engenharia de Sistemas de Potência e Automação, instituto superior de engenharia de Lisboa, Lisboa.

[13] ALTERNE (Europa). energia fotovoltaica, manual sobre tecnologias, projeto e instalação. 1. ed, Janeiro de 2004.

[14] RAMPINELLI, G. A.; KRENZINGER, A.. EFEITO DO SOMBREAMENTO EM CÉLULAS DE UMA ASSOCIAÇÃO DE MÓDULOS FOTOVOLTAICOS CONECTADOS À REDE. Avances en Energías Renovables y Medio Ambiente, Argentina, v. 10, p. 4, jan. 2006.

[15] RONCOLATTO, R. A. et al. PROJETO TELHADOS SOLARES - METODOLOGIA PARA ELABORAÇÃO DE PROJETOS, MONTAGEM E INSPEÇÃO DE INSTALAÇÕES FOTOVOLTAICAS. Em: Congresso Brasileiro de Energia, $7^{\circ}, 2018$, Gramado.

[16] ASSOCIAÇÃO BRASILEIRA DE NORMAS TÉCNICAS. NBR 8039. Rio de Janeiro, 1983. 5p.

[17] UALG.PT. Materiais de construção. Disponível em: <http://w3.ualg.pt/ ealmeida/materiais\%20de\%20 constru\%c3\%a7\%c3\%a3o/np\%20494.pdf>. Acesso em: 15 mar. 2019.

[18] ETERNIT a marca da coruja. CATÁLOGO TÉCNICO FIBROCIMENTO. Disponível em: $<$ https://www.eternit.com.br/downloads/catalogos/CATALOGO-ETERNIT-FIBROCIMENTO-CRFSWEB.pdf>.

[19] GIL, Antonio Carlos. Como elaborar projetos de pesquisa. 5 ed. SÃO CAETANO DO SUL: ATLAS, 2010. 26-43 p.

[20] BRASILEIRO, Ada. Manual de produção de textos acadêmicos e científicos. São Paulo: Atlas 2013.

[21] GEOGRAFOS. Mossoró, rio grande do norte-rn.. Disponível em: <https://www.geografos.com.br/cidades-rio-grande-norte/mossoro.php>. Acesso em: 08 fev. 2019.

[22] RADIASOL2: SOLARCARD. 2. UFRGS, Porto Alegre, RS, 2010. Acesso em: 13 fev. 2019.

[23] COUTINHO, A. L. M. telhados de edificações habitacionais: 2018. 128p. Dissertação (Graduação) centro de tecnologia, Universidade Federal de Santa Maria. 